Table 1. Comparative characteristics of Group 1 and Group 2 AS patients.

\begin{tabular}{lccc}
\hline & Group 1 (n=220) & Group 2 (n=9) & p \\
\hline Mean age, M \pm a, y. & $35,1 \pm 9,5$ & $40,1 \pm 8,6$ & $>0.05$ \\
Mean age at the onset, $\mathrm{M} \pm$ a, y. & $29,9 \pm 9,6$ & $13,4 \pm 7,5$ & $<\mathbf{0 . 0 5}$ \\
Mean disease duration, $\mathrm{M} \pm \mathrm{a}, \mathrm{y}$. & $6,9 \pm 5,6$ & $26,3 \pm 6,5$ & $<\mathbf{0 . 0 5}$ \\
Men, $\mathrm{n}(\%)$ & $162(73,6 \%)$ & $9(100 \%)$ & $<\mathbf{0 . 0 5}$ \\
HLA B27, $\mathrm{n}(\%)$ & $202(91,8 \%)$ & $9(100 \%)$ & $>0.05$ \\
Arthritis, $\mathrm{n}(\%)$ & $182(82,7 \%)$ & $9(100 \%)$ & $<\mathbf{0 . 0 5}$ \\
Coxitis, $\mathrm{n}(\%)$ & $119(54,0 \%)$ & $9(100 \%)$ & $<\mathbf{0 . 0 5}$ \\
Enthesitis, $\mathrm{n}(\%)$ & $105(47,7 \%)$ & $7(78 \%)$ & $>0.05$ \\
Uveitis, $\mathrm{n}(\%)$ & $52(23,6 \%)$ & $4(44,4 \%)$ & $>0.05$ \\
IBD, $\mathrm{n}(\%)$ & $5(2,2 \%)$ & 0 & $>0.05$ \\
Psoriasis, $\mathrm{n}(\%)$ & $24(10,9 \%)$ & 0 & $>0.05$ \\
\hline
\end{tabular}

Conclusion: Patients with AS and secondary AA amyloidosis are predominantly of male gender, who usually get sick in childhood, have 100\% HLA-B27 positivity, peripheral arthritis, and coxitis.

Disclosure of Interests: None declared

DOI: 10.1136/annrheumdis-2020-eular.3209

\section{AB0720 SOLUBLE TRANSFERRIN RECEPTOR IN DIAGNOSIS OF IRON DEFICIENCY ANEMIA IN PATIENTS WITH SPONDYLOARTHRITIS}

K. Safarova ${ }^{1}$, A. Rebrov ${ }^{2} .{ }^{1}$ Saratov State Medical University named after V.I. Razumovsky, Chair of Hospital Therapy, Saratov, Russian Federation; ${ }^{2}$ Saratov State Medical University named after V.I. Razumovsky, Chair of Hospital Therapy, Saratov, Russian Federation

Background: Anemia is a frequent hematological disorder in patients with rheumatic diseases. The main pathogenetic variants of anemia are anemia of chronic disease (ACD), iron deficiency anemia (IDA), and anemia of chronic disease with iron deficiency (ACD/IDA). The presence of systemic inflammation hinders to diagnose absolute iron deficiency, because standard tests of iron status are affected by it. Soluble transferrin receptors (sTfR) measurement and the calculation of the sTfR/ log ferritin index (sTfR index) are recommended, but data about diagnostically significant levels of these indicators in patients with spondyloarthritis (SpA) is currently limited.

Objectives: To assess the diagnostic significance of sTfR and the sTfR index for detecting absolute iron deficiency in patients with SpA and anemia.

Methods: Complete blood count, standart iron metabolism parameters, C-reactive protein (CRP) and erythrocyte sedimentation rate (ESR) were evaluated in 68 patients with SpA. Serum concentration of STfR was measured with enzymelinked immunosorbent assay (ELISA) using sTfR ELISA kit («Monobind Inc.», USA). The sTfR index was calculated by the formula sTfR/ $\log _{10}$ ferritin. Anemia was defined using the World Health Organization criteria. Depending on the serum ferritin concentration, transferrin saturation, and CRP level, ACD, IDA, or combined anemia (ACD/IDA) were diagnosed. Disease activity was determined by the BASDAI (Bath Ankylosing Spondylitis Disease Activity Index) and ASDASCRP (Ankylosing Spondylitis Disease Activity Score based on CRP) scales. Receiver operating characteristic $(\mathrm{ROC})$ analysis was performed with MedCalc. Results: Anemia was found in 48 of $68(70,6 \%)$ SpA patients. $16(33,3 \%)$ patients had ACD and 32 (66,7\%) had ACD/IDA. Hemoglobin level in ACD was 118 [112; 123] g/L, in ACD/IDA - 110 [106; 120] g/L, in non-anemic patients - 133 [129; 145] g/L ( $p<0.001$ for all groups). CRP and ESR values were higher in ACD compared to ACD/IDA patients (31.5 [20.3; 46.4] mg/L and $27.0[16.0 ; 35.5] \mathrm{mm} / \mathrm{h}$ versus $9.8[5.6 ; 16.9] \mathrm{mg} / \mathrm{L}$ and 15.5 $[12.0 ; 22.5] \mathrm{mm} / \mathrm{h}$, respectively $[\mathrm{p}=0.00$ and $\mathrm{p}=0.038])$. No statistically significant difference was found between all groups in BASDAI and ASDAS-CRP scores.

ACD/IDA patients had significant increases in serum sTfR levels $(1.7[1.4 ; 2.2]$ $\mathrm{mg} / \mathrm{L})$ compared to $\operatorname{ACD}(1.5[1.1 ; 1.7] \mathrm{mg} / \mathrm{L}, \mathrm{p}=0,04)$ and to non-anemic patients $(1,3[1,1 ; 1,6] \mathrm{mg} / \mathrm{L}, \mathrm{p}=0,003)$. The sTfR index was significantly higher in ACD/ IDA $(0.93$ [0.82; 1.24]) compared to patients with ACD $(0.64$ [0.48; 0.75], $\mathrm{p}<0.001)$ and without anemia $(0.67[0.56 ; 0.81], p<0.001)$.

The areas under the curves (AUCs) for distinguishing between ACD/IDA and ACD were 0.85 for $s$ TfR index $(p<0,001), 0.72$ for $\operatorname{sTfR}(p<0,001)$. The $s$ TfR index (cutoff $>0.83$ ) and sTfR (cutoff $>1.39 \mathrm{mg} / \mathrm{L}$ ) had sensitivities of $75 \%$ and $53 \%$, and specificities of $83 \%$ and $81 \%$, respectively.

Conclusion: According to obtained data, serum concentration of STfR $>1.39 \mathrm{mg} / \mathrm{L}$ and the sTfR index $>0.83$ point to the presence of iron deficiency component in the structure of anemic syndrome in patients with $\mathrm{SpA}$.

References: Management of patients with SpA requires constant monitoring of side effects of therapy, in particular induced by the non-steroidal anti-inflammatory drugs. Use of sTfR and the sTfR index can improve the detection of IDA. A significant advantage of these indicators is their independence from systemic inflammation.

Disclosure of Interests: None declared

DOI: 10.1136/annrheumdis-2020-eular.3608 \begin{tabular}{|l|l}
\hline AB0721 & OCULAR INVOLVEMENT IN INFLAMMATORY BOWEL \\
DISEASE. STUDY OF 1442 PATIENTS FROM A SINGLE
\end{tabular} DISEASE. STUDY OF 1442 P
UNIVERSITARY CENTER.

L. Sanchez-Bilbao ${ }^{1}$, D. Martinez-Lopez ${ }^{1}$, I. González-Mazón ${ }^{1}$, M. J. GarcíaGarcía $^{2}$, M. Rivero-Tirado ${ }^{2}$, B. Castro ${ }^{2}$, J. Crespo², M. A. González-Gay ${ }^{1}$,

R. Blanco ${ }^{1} .{ }^{1}$ H.U. Marqués de Valdecilla, Rheumatology, Santander, Spain; ${ }^{2}$ H.U. Marqués de Valdecilla, Gastroenterology, Santander, Spain

Background: Inflammatory bowel disease (IBD), which includes Crohn's disease (CD), and Ulcerative colitis (UC) are related to Spondyloarthritis ( $\mathrm{SpA}$ ). Ocular manifestations (OM) are well-stablished in SpA but not in IBD. It has been classically reported that whereas uveitis with $\mathrm{SpA}$ is predominantly anterior, unilateral, sudden, and limited; in IBD it is bilateral, posterior, insidious, and chronic (Lyons \& Rosenbaum JT. Arch Ophthalmol 1997; 115:61-4).

Objectives: In a large unselected series of IBD, we study the OM and assess; a) epidemiological, clinical features, b) the relationship with extraintestinal manifestations.

Methods: Study of all consecutive patients from a single University Hospital during the last 40 years with: a) IBD (CD and $\mathrm{UC}$ ), and b) OM: uveitis and scleral pathology diagnosed by clinical features and slit-lamp.

Results: OM were present in 42 (2.9\%) (25 women/17 men) (84 eyes) of 1442 IBD patients; OM included the uveitis group (UG) $(n=23 ; 1.6 \%)$ and the scleral pathology group (SG) $(n=19,1.32 \%)$ (TABLE).

TABLE.

\begin{tabular}{|c|c|c|c|}
\hline & $\begin{array}{l}\text { Uveitis } \\
(n=23)\end{array}$ & $\begin{array}{c}\text { Epi/scleritis } \\
(n=19)\end{array}$ & $\mathbf{p}$ \\
\hline \multicolumn{4}{|l|}{ DEMOGRAPHIC PARAMETERS } \\
\hline Sex, n (\%) & 6 o / 17 ㅇ & 11 o / 8 \% & $\mathrm{p}=0.04^{\star}$ \\
\hline $\begin{array}{l}\text { Age at diagnosis (years) mean } \pm \mathrm{SD} \\
\text { INTESTINAL AFFECTION }\end{array}$ & $49.13 \pm 14.64$ & $47.63 \pm 12.48$ & $p=0.415$ \\
\hline $\mathrm{CD}, \mathrm{n}(\%)$ & $12(52.17)$ & $16(84.21)$ & $p=0.02^{*}$ \\
\hline UC, $n(\%)$ & $11(47,83)$ & $3(15,74)$ & $p=0.16$ \\
\hline \multicolumn{4}{|l|}{ EXTRAINTESTINAL AFFECTION } \\
\hline Cutaneous manifestations & & & \\
\hline •Erythema nodosum, n (\%) & $6(26.09)$ & $2(10.53)$ & $p=0.30$ \\
\hline -Pyoderma gangrenosum, $\mathrm{n}(\%)$ & $1(4.35)$ & $0(0)$ & $\mathrm{p}=0.92$ \\
\hline -Psoriasis, n (\%) & $1(4.35)$ & $4(21.01)$ & $p=0.23$ \\
\hline Joint involvement & $10(43.50)$ & $6(31.60)$ & $p=0.36$ \\
\hline •Psoriathic arthritis, n (\%) & $1(4.35)$ & $3(15.80)$ & $p=0.47$ \\
\hline -Enteropathic Spondyloarthritis, n (\%) & $6(26.09)$ & $3(15.80)$ & $p=0.66$ \\
\hline -Ankylosing Spondylitis, $n(\%)$ & $3(13.04)$ & $0(0)$ & $p=0.28$ \\
\hline \multicolumn{4}{|l|}{ Digestive manifestations } \\
\hline •NASH, n(\%) & $4(17.39)$ & $6(31.58)$ & $p=0.28$ \\
\hline
\end{tabular}

${ }^{*} \mathrm{p}$ value $<0.05$. SD: standard deviation; CD: Crohn's disease; UC: ulcerative colitis; NASH: non-alcoholic steatohepatitis.

The most common pattern in SG was episcleritis $(n=16 ; 84.21 \%)$ and scleritis $(n=3)$. In UG, uveitis was typically anterior $(n=18 ; 78.3 \%)$, unilateral $(n=19$; $82.6 \%)$, sudden $(n=19 ; 82.6 \%)$, and limited $(n=12 ; 52.2 \%)$.

The comparative study between SG vs UG showed in UG a significant predominance of women and UC. Also, a non-significative higher frequency in Pyoderma gangrenosum, erythema nodosum and joint involvement was observed in UG. After a mean follow-up of $15.2 \pm 9.97$ years, extraintestinal manifestations were observed in $100 \%$ of patients, being articular forms ( $n=16 ; 38.10 \%$ ) the most common type. In addition, joint/axial flare is more related to the presence of uveitis $(p=0.038)$. Conclusion: Both uveitis and episcleritis are equally frequent $\mathrm{OM}$ in IBD. Although uveitis is more infrequent in IBD than in SpA, it is also anterior, unilateral, sudden and limited in contrast with published data from selected series. References:

[1] Lyons \& Rosenbaum JT. Arch Ophthalmol 1997; 115:61-4

Disclosure of Interests: Lara Sanchez-Bilbao Grant/research support from: Pfizer David Martinez-Lopez: None declared, Iñigo González-Mazón: None declared, María José García-García: None declared, Montserrat Rivero-Tirado: None declared, Beatriz Castro: None declared, Javier Crespo: None declared, Miguel A González-Gay Grant/research support from: Pfizer, Abbvie, MSD, Speakers bureau: Pfizer, Abbvie, MSD, Ricardo Blanco Grant/research support from: AbbVie, MSD, and Roche, Speakers bureau: AbbVie, Pfizer, Roche, Bristol-Myers, Janssen, and MSD DOI: 10.1136/annrheumdis-2020-eular.4612

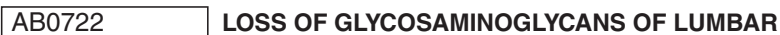 INTERVERTEBRAL DISCS IN PATIENTS WITH ANKYLOSING SPONDYLITIS}

P. Sewerin ${ }^{1}$, D. Abrar ${ }^{2}$, M. Frenken ${ }^{2}$, X. Baraliakos ${ }^{3}$, M. Schneider ${ }^{1}$, B. Ostendorf ${ }^{1}$, C. Schleich ${ }^{2} .{ }^{1}$ Heinrich-Heine University, Department for Rheumatology, Duesseldorf, Germany; ${ }^{2}$ Heinrich-Heine University, Institute 